\title{
Evaluating 2 Year Outcome in Twins $\leq 30$ Weeks Gestation at Birth: A Regional Perinatal Unit's Experience
}

\author{
Elizabeth V.Asztalos ${ }^{1,3,4}$, Jon F. R. Barrett ${ }^{2,4}$, Maralyn Lacy ' and Maureen Luther' \\ ' Neonatal Follow-up Program, Sunnybrook \& Women's College Health Sciences Centre \\ ${ }^{2}$ Department of Obstetrics \& Gynecology \\ ${ }^{3}$ Department of Newborn \& Developmental Medicine \\ ${ }^{4}$ University of Toronto
}

W th improved technology in assisted reproductive medicine, there has been an absolute increase in the numbers of twin pregnancies with an associated increase in perinatal mortality and morbidity. This increase in perinatal mortality and morbidity is largely due to a higher incidence of delivering preterm as compared to singletons. Twin pregnancies have their unique complications that include abnormal placental communication and discordant growth which are associated with perinatal mortality and morbidity. The objectives of this study were two-fold: i) to determine if the morbidity/mortality outcome at 18-24 months corrected age seen in a cohort of twins born between 24-30 weeks gestation was significantly different as compared to singleton preterm infants of the same gestation; and ii) to determine and evaluate any differences between monochorionic (MC) and dichorionic (DC) twins. Twins 24-30 weeks gestation at birth born between 01/01/97-30/06/99 were identified and prospectively followed to 18-24 months corrected age (c.a.). They were matched with a singleton infant of the same gender and within 1 week of the same gestation. Obstetrical, neonatal and neurodevelopmental data were gathered and analyzed. The primary outcome was death or the presence of a severe neurodevelopmental deficit at 18-24 months corrected age. Of the 56 sets of twins identified, 52 sets were followed prospectively with 101 infants available for matching. In this cohort, twin pregnancies had a lower incidence of pregnancy-induced hypertension and premature rupture of membranes than singletons $(p<0.05)$. The two groups were comparable in neonatal characteristics. The incidence of death or severe disability was $29.7 \%$ in twins vs. $22.8 \%$ in singletons ( $p=0.337$, Fisher's exact test). The major area of deficit was in the cognitive category for both groups, $9.9 \%$ vs. $7.9 \%$ respectively. MC twins made up 35.6\%; DC twins $64.4 \%$. Twin to twin transfusion syndrome (TTTS) occurred in $6.9 \%$. Discordant growth occurred more frequently in $M C$ pregnancies $(p=0.016)$. MC twins tended to be more premature, lower in birth weight, and experience neonatal morbidity in the form of patent ductus arteriosus and sepsis $(p<$ 0.05 ) as compared to DC twins. However, the primary outcome of death or severe neurodevelopmental deficit at 18-24 months c.a. was not significantly different between the two groups, $38.9 \%(\mathrm{MC})$ vs. $24.6 \%(\mathrm{DC}),(p=0.173$, Fisher's exact test). Neurodevelopmental morbidity or mortality in twins with TTTS was $42 \%$. Mortality and severe neurodevelopmental morbidity were not significantly higher in twins as compared to singletons in this cohort. However, the trend is slightly higher in twins, which may have clinical significance. Though not statistically significant, the incidence of $38.9 \%$ in adverse outcome with MC twins may be clinically significant. With the number of twins steadily increasing, further monitoring is required to determine future directions in intervention and research. Early recognition of monochorionicity remains essential to optimize care and neurodevelopment for these infants.

Improved technology in reproductive medicine and obstetrical and neonatal medicine has led to an increase in the absolute numbers of multiple fetus $(\geq 2)$ pregnancies. Multiple fetus pregnancies account for an increasing percentage of low birth weight infants and preterm delivery with its associated increase in perinatal mortality and morbidity (McCormick, 1985; Robertson, 1992). Preterm, LBW infants are at higher risk of infant mortality and neurodevelopmental difficulties. While only 3\% of births in the United States were multiple births, these 3\% accounted for $21 \%$ of all LBW births, $14 \%$ of preterm births, and $13 \%$ of infant deaths (MacDorman, 1997; Ventura, 1997). A similar trend is seen in Canada where data indicated that the preterm birth rate has risen much faster among multiple births as compared to singleton births (Joseph, 1998).

Twin pregnancies have unique difficulties that put them at a higher risk for adverse outcomes which include abnormal placental communication and discordant growth (Powers, 1994; Sonntag, 1996). Past literature has suggested that monochorionic twins are at higher risk for morbidity and mortality (Sonntag, 1996; Victoria, 2001).

There is a growing body of literature on the management and immediate outcome of twin pregnancies. Literature on neurodevelopmental outcome on twins has focused primarily on neuromotor deficits such as cerebral palsy. Research has indicated that twins have an increased risk of cerebral palsy as compared to singletons (Pharaoh, 1996; Scheller, 1992; Williams, 1996). Although prematurity and low birthweight play a role, they may not account entirely for the increased risk (William, 1996).

Address for correspondence: Elizabeth V. Asztalos MD FRCPC, Department of Newborn \& Developmental Medicine, Sunnybrook \& Women's College Health Sciences Centre, 76 Grenville Street Room 466, Toronto, Ontario, Canada M5S1B2. E-mail: elizabeth.asztalos@swchsc.on.ca 
Monochorionicity has been identified as a risk factor for the development of cerebral palsy (Burguet, 1999).

With the increasing numbers of smaller and immature infants of twin pregnancies, it is important to know whether the advances in obstetrical management and subsequent neonatal care of the very low birth weight twin infant are leading to improved neurodevelopmental outcomes than previously reported.

The objective of this study was to determine if the mortality/morbidity outcome seen in a cohort of twins born between 24-30 weeks gestation was significantly different as compared to singleton preterm infants of the same gestation and to determine if differences existed between monochorionic (MC) and dichorionic (DC) twins in this gestation grouping

\section{Methods}

This study was performed at the regional perinatal center at Sunnybrook \& Women's College Health Sciences Centre (SWCHSC). The hospital is one of two tertiary perinatal referral centers in metropolitan Toronto, which serves Toronto and the Central East region of Ontario, Canada. Approximately 3500 births occur annually in this center with more that 68,000 occurring in the region. The Research Ethics Board of the study institution approved the research protocol.

\section{Table 1}

Rules for Matching

\begin{tabular}{ll}
\hline & \multicolumn{1}{c}{ Rules for Matching } \\
\hline 2. & $\begin{array}{l}\text { Gender } \\
\text { Gestational age: index and control were within } \\
\text { one }(+-) \text { completed weeks }\end{array}$ \\
3. & $\begin{array}{l}\text { Control infant had to have a known outcome: } \\
\text { either death or 18-24 month outcome }\end{array}$ \\
4. & $\begin{array}{l}\text { Date of birth for control was within six months after index } \\
\text { case's birth; if none present, then went back } 3 \text { months from } \\
\text { date of birth of index case }\end{array}$ \\
\hline
\end{tabular}

Twins of 24-30 weeks gestation, born between January 1, 1997 and June 30, 1999 and admitted to the Neonatal Intensive Care Unit (NICU) at SWCHSC, were included. Each twin was matched with a singleton infant of the same gender and within 1 week of the same gestational age at birth. The rules for matching are outlined in Table 1. Obstetrical and neonatal data were extracted from the maternal and neonatal charts.

All infants were followed regularly to 18-24 months corrected age. Corrected age was defined as the age in weeks or months from the estimated date of confinement for the pregnancy. During this time, interval assessments at corrected age ( 6 weeks, $4,8,12$, and 18 to 24 months) were made to determine the presence of a neurodevelopmental deficit. A severe visual deficit was defined as vision $<20 / 200$ in one or both eyes. A severe hearing deficit was defined as the need for amplification or insertion of cochlear implants. A severe motor deficit was defined as the presence of abnormal tone preventing ambulation consistent with cerebral palsy. A severe cognitive deficit was based on a score of less than 2 standard deviations from the mean as determined by the Bayley Scales of Infant DevelopmentII (BSID-II) (Bayley, 1993). For those infants who could not be tested formally, cognition was assessed informally in person using the items of the BSID-II and judged by the examiner as being normal, or having a mild or severe deficit. One individual, certified by the American Psychological Corporation, conducted the BSID-II assessments. The presence of abnormal tone was determined by the developmental neonatologist of the Follow-up Clinic. Visual impairment was confirmed by the ophthalmologists in the tertiary retinopathy of prematurity (ROP) clinic at the Hospital for Sick Children in Toronto, Canada. Hearing impairment was confirmed by the audiology service at the same institution.

For the obstetric data, the attending staff obstetricians made clinical diagnoses according to standard definition. Gestational age was determined by either date of last menstrual period or early ultrasound ( $<20$ weeks gestation); if there were cases where gestation differed, the early ultrasound was " the gold standard".

Table 2

Definitions of Neonatal Morbidities

Neonatal Morbidity Definition

Respiratory Distress Syndrome (RDS)

Patent Ductus Arteriosus (PDA)

Intraventricular Hemorrhage (IVH)

Periventricular Leukomalacia (PVL)

Necrotizing Enterocolitis (NEC)

Retinopathy of Prematurity (ROP)

Respiratory distress requiring oxygen therapy is present beyond the first 24 hours of life, may require surfactant, and has typical radiographic signs (Fanaroff and Martin, 1997)

Clinical murmur, hyperdynamic precordium and peripheral pulses, widened pulse pressures, hemodynamic finding on 2-D echocardiography, may require treatment or ligation

Confirmed by cranial ultrasound: grade 1 involving germinal matrix hemorrhage, grade 2 IVH involving $10-50 \%$ of ventricular are, grade 3 involving IVH occupying $>50 \%$ of the ventricular area, grade 4 involving hemorrhagic involvement of adjacent white matter (Volpe, 1995)

Confirmed by cranial ultrasound: evidence of white matter injury (Volpe, 1995)

Clinical gastrointestinal disturbances associated with pneumatosis intestinalis on abdominal radiography (Bell et al., 1978)

Defined on the basis of the criteria of the Committee for the Classification of Retinopathy of Prematurity (The Committee for the Classification of Retinopathy of Prematurity, 1984)

Sepsis Infection confirmed by positive blood culture 
Neonatal clinical diagnoses were made by the attending staff neonataologists according to standard definitions (Bell et al., 1978; Fanaroff \& Martin, 1997; The Committee for the Classification of Retinopathy of Prematurity, 1984; Volpe, 1995) and are described in Table 2. Small for gestational age (SGA) was defined as a birth weight less than 2 standard deviations from the mean for the gestational age (Usher \& McLean, 1969).

The primary outcome was the presence of a severe neurodevelopmental deficit in any of the four categories (vision, hearing, motor skills, and cognition) or death by 18-24 months corrected age.

\section{Analysis}

Descriptive statistics (means, standard deviations, and proportions) were used to describe the two groups of infants. To determine a difference in the primary outcome, the proportion of infants who died or had an identified deficit was compared using a Fisher's exact test. The proportions of secondary outcomes, maternal and neonatal morbidities were compared using Chi-Square statistics. The level of significance was set at 0.05 .

MC and DC twins were compared separately to their matched singletons using a Fisher's exact test and subsequently verifying the results with the McNemar's test. The McNemar's test used the matched pair as the unit of analysis rather than the individual subject. Logistic regression was performed on those neonatal outcomes found significant to ensure the significance found was due to the type of twin and not an imbalance in confounding factors.

\section{Results}

From January 1, 1997 to June 30, 1999, 56 sets of twins were admitted to the NICU. Of these, 4 sets were not followed (1 set moved out of the country, 3 sets were lost to follow-up). This left a total of 52 sets of twins; in 3 sets, one of the fetuses was stillborn, leaving a total of 101 infants who were followed prospectively to $18-24$ months corrected age. These infants were then matched with the singleton controls.

With respect to chorionicity, 35.6\% were monochorionic, $64.4 \%$ were dichorionic. Twin-to-twin transfusion syndrome occurred in $6.9 \%$ of the twins. In terms of gender, $46 \%$ were male and $54 \%$ were female. The distribution of the twins according to gestational age is seen in

\section{Table 3}

Distribution of Gestational Age (Completed Weeks) Among Twin Cohort

\begin{tabular}{cc}
\hline Gestational age (weeks) & Number (total $n=52$ ) \\
\hline 24 & 6 \\
25 & 5 \\
26 & 10 \\
27 & 9 \\
28 & 8 \\
29 & 8 \\
30 & 6
\end{tabular}

Table 3; the average gestational age for both the twin and singleton cohorts was 27.1 weeks. The results will be presented in two parts: twins vs. singletons; monochorionic twins vs. dichorionic twins.

\section{Twins vs. Singletons}

\section{Obstetrical Outcomes}

The singleton and twin pregnancies were compared with respect to the more common maternal morbidities as outlined in Table 4. In this cohort, singleton pregnancies experienced a higher incidence of pregnancy-induced hypertension and premature rupture of membranes as compared to twin pregnancies. Otherwise, twin pregnancies were not seen as having significantly more morbidity.

There was a higher rate of Caesarean sections in the twins cohort, $48.5 \%$ as compared to $40.6 \%$ in singleton pregnancies.

\section{Neonatal Morbidity}

Tables $5 \mathrm{a} / \mathrm{b}$ compare the incidence of major neonatal morbidity between the twins and the singletons groups. For most morbidities, a significant difference could not be demonstrated except for the incidence of necrotising enterocolitis, which was significantly higher in the twins cohort. It should be noted that for most of the morbidities, there was a trend towards higher incidence in the twins group as compared to the singletons

\section{Neurodevelopmental Outcome}

The primary outcome for this study was death or the presence of a severe neurodevelopmental deficit at 18-24

\section{Table 4}

Maternal Morbidities

\begin{tabular}{lccc}
\hline & $\begin{array}{c}\text { Twins } \\
(n=101) \\
\%\end{array}$ & $\begin{array}{c}\text { Singletons } \\
(n=101) \\
\%\end{array}$ & $p$-value \\
\hline Pregnancy-induced & 6.9 & 15.8 & 0.046 \\
$\begin{array}{l}\text { Hypertension (PIH) } \\
\text { Antepartum Hemorrhage (APH) }\end{array}$ & 15.8 & 24.7 & 0.115 \\
Preterm Labor (PTL) & 79.2 & 75.3 & 0.502 \\
$\begin{array}{l}\text { Premature Rupture } \\
\text { of Membranes (PROM) }\end{array}$ & 22.2 & 41.6 & 0.003 \\
$\begin{array}{l}\text { Intrauterine Growth } \\
\text { Retardation (IUGR) }\end{array}$ & 13.8 & 14.9 & 0.841 \\
\hline
\end{tabular}

\section{Table 5a}

Neonatal Characteristics

\begin{tabular}{lccc}
\hline & $\begin{array}{c}\text { Twins } \\
(n=101) \\
\text { mean }(S D)\end{array}$ & $\begin{array}{c}\text { Singletons } \\
(n=101) \\
\text { mean }(S D)\end{array}$ & $p$-value \\
\hline Birth weight (gm) & $1001.7(306.6)$ & $978.9(262.6)$ & 0.123 \\
\hline & $\%$ & $\%$ & \\
\hline Birth weight (3rd\%ile) & 15.8 & 15.8 & 1.00 \\
Survival (to 18-24 months) & 81.2 & 88.1 & 0.172 \\
Use of surfactant & 41.6 & 54.9 & 0.082 \\
Use of dexamethasone & 30.3 & 21.9 & 0.213 \\
\hline
\end{tabular}


Table 5b

Neonatal Morbidities

\begin{tabular}{lccc}
\hline & $\begin{array}{c}\text { Twins } \\
(n=101) \\
\%\end{array}$ & $\begin{array}{c}\text { Singletons } \\
(n=101)\end{array}$ & $p$-value \\
\hline RDS & 59.8 & 51.7 & 0.289 \\
PDA & 46.3 & 37.1 & 0.219 \\
Sepsis & 14.6 & 16.9 & 0.691 \\
IVH & 42.7 & 33.7 & 0.227 \\
PVL & 4.9 & 1.1 & 0.145 \\
ROP & 46.1 & 35.9 & 0.181 \\
NEC & 7.3 & 1.1 & 0.041 \\
\hline
\end{tabular}

months corrected age. The incidence of death or a severe neurodevelopmental outcome for the twins cohort was $29.7 \%$ vs. $22.8 \%$ for the singletons cohort; this was not found to be significant using both the Fisher's exact test ( $p$ $=0.337)$ and the McNemar's test $(p=0.162)$. Table 6 outlines the distribution of the outcome measures. Both groups were essentially very similar in the distribution of severe deficits. Although not found to be significant, there was a trend in the twins group for a higher incidence in hearing loss.

\section{B. Monochorionic vs. Dichorionic \\ Obstetrical Outcomes}

$\mathrm{MC}$ and DC twin pregnancies were compared with respect to the more common maternal morbidities as outlined in Table 7. DC twin pregnancies experienced a higher incidence of pregnancy-induced hypertension and antepartum hemorrhage, in the form of abruptio placentae as compared to $\mathrm{MC}$ pregnancies. MC pregnancies had a significantly higher incidence of growth restricted fetuses. Otherwise there were no significant differences between the two groups in the other morbidities. There was a higher rate of Caesarian section for MC twins, $58.3 \%$, as compared to $43.1 \%$ in DC twins.

\section{Neonatal Outcomes}

Tables 8a/b compares the incidence of major neonatal morbidity between the two groups of twins. In general, $\mathrm{MC}$

\section{Table 6}

Distribution of Death and Neurodevelopmental Morbidity

\begin{tabular}{lccc}
\hline & $\begin{array}{c}\text { Twins } \\
(n=101) \\
\#(\%)\end{array}$ & $\begin{array}{c}\text { Singletons } \\
(n=101) \\
\#(\%)\end{array}$ & $p$-value \\
\hline Death or severe outcome & $30(29.7)$ & $23(22.8)$ & $0.337^{*}$ \\
Death & $20(19.8)$ & $12(11.9)$ & 0.236 \\
Vision impairment & $1(1.23)$ & $1(1.12)$ & 0.881 \\
Hearing impairment & $6(7.41)$ & $1(1.12)$ & 0.078 \\
Cerebral palsy & $5(6.17)$ & $4(4.49)$ & 0.777 \\
Cognitive impairment & $8(9.88)$ & $7(7.87)$ & 0.132 \\
\hline * Fisher's exact test & & &
\end{tabular}

\section{Table 7}

Maternal Morbidities

\begin{tabular}{|c|c|c|c|}
\hline & $\begin{array}{c}\text { Monochorionic } \\
\qquad \begin{array}{c}(n=36) \\
\%\end{array}\end{array}$ & $\begin{array}{c}\text { Dichorionic } \\
\quad(n=65) \\
\%\end{array}$ & $p$-value \\
\hline $\begin{array}{l}\text { Pregnancy-induced } \\
\text { Hypertension (PIH) }\end{array}$ & 0 & 10.8 & 0.041 \\
\hline Antepartum Hemorrhage (APH) & 2.8 & 23.1 & 0.0007 \\
\hline Preterm Labor (PTL) & 75.0 & 81.5 & 0.438 \\
\hline $\begin{array}{l}\text { Premature Rupture } \\
\text { of Membranes (PROM) }\end{array}$ & 29.4 & 18.5 & 0.213 \\
\hline $\begin{array}{l}\text { Intrauterine Growth } \\
\text { Retardation (IUGR) }\end{array}$ & 25.0 & 7.7 & 0.016 \\
\hline
\end{tabular}

twins were of lower gestational age and birth weight and required ventilation support for almost two weeks more than DC twins. The use of surfactant in the MC group was slightly higher but not statistically significant. However, the use of dexamethasone in the MC group was significantly higher. This significance remained after controlling for birth weight in a logistics regression. The adjusted odds ratio was $3.99(1.145,13.91995 \% \mathrm{CI})$ indicating that MC twins were 4 times as likely to receive dexamethasone as DC twins. The MC group experienced a significantly higher incidence of PDA and sepsis as compared to the DC group. The significance between the two groups in proportion with a PDA remained; but sepsis was no longer

\section{Table 8a}

Neonatal Characteristics

\begin{tabular}{lccc}
\hline & $\begin{array}{c}\text { Monochorionic } \\
(n=36) \\
\text { mean }(S D)\end{array}$ & $\begin{array}{c}\text { Dichorionic } \\
(n=65)\end{array}$ & $p$-value \\
& mean $(S D)$ & \\
\hline Birth weight (gm) & $873.8(289.3)$ & $1072.5(294.7)$ & 0.001 \\
Gestational age (weeks) & $26.25(1.6)$ & $27.6(1.8)$ & 0.003 \\
& $(\%)$ & $(\%)$ & \\
\hline Birth weight (3rd\%ile) & 22.2 & 12.3 & 0.191 \\
Use of Surfactant & 64.3 & 50.0 & 0.218 \\
Use of Dexamethasone & 42.7 & 11.1 & 0.001 \\
\hline
\end{tabular}

\section{Table 8b}

Neonatal Morbidities

\begin{tabular}{lccc}
\hline & $\begin{array}{c}\text { Monochorionic } \\
(n=36) \\
\%\end{array}$ & $\begin{array}{c}\text { Dichorionic } \\
(n=65) \\
\%\end{array}$ & $p$-value \\
\hline RDS & 64.3 & 57.4 & 0.547 \\
PDA & 75.0 & 31.5 & 0.001 \\
Sepsis & 28.6 & 7.4 & 0.01 \\
IVH /PHV & $35.7 / 10.7$ & $46.3 / 1.9$ & $0.358 / 0.077$ \\
PVL & 3.6 & 5.6 & 0.692 \\
ROP & 53.9 & 42.3 & 0.335 \\
NEC & 10.7 & 5.6 & 0.395 \\
\hline
\end{tabular}


significant once birth weight was controlled for. The adjusted odds ratio was $5.0(1.7,14.695 \% \mathrm{CI})$ indicating that the $\mathrm{MC}$ group was 5 times more likely to experience a PDA as the DC group. There was a trend in the incidence of the remaining morbidities, apart from PVL, to be higher in the MC group but these were not statistically significant. None of the infants who experienced post-hemorrhagic ventriculomegaly required a shunt.

\section{Neurodevelopmental Outcome}

The primary outcome of this study was death or the presence of a severe neurodevelopmental deficit at 18-24 months corrected age. The incidence of death or a severe neurodevelopmental outcome for the MC group was $38.9 \%$ vs. $24.6 \%$ for the DC groups; this was not found to be significant using the Fisher's exact test $(p=0.173)$. The primary outcome of death or the presence of severe neurodevelopmental deficit was also analysed in relation to those twins who received dexamethasone during their neonatal care. Those twins, either MC or DC, who received dexamethasone tended to have a poorer outcome as compared to those who did not receive dexamethasone, $27.8 \%$ vs. $9.4 \%$ using Mantel-Haenszel Chi-Square ( $p=$ $0.04)$.

Table 9 outlines the distribution of the outcome measure. Both groups were very similar in the distribution of death and severe deficits. Although not found to be significant, there was a trend in the MC group for a higher incidence in cognitive, hearing and motor deficits. Twin-totwin transfusion syndrome occurred in only $6.9 \%$ of the pregnancies. However, the incidence of death or severe neurodevelopmental deficit was $42.9 \%$ in this group.

The twin groups were individually compared with respect to the primary outcome to their matched singletons. The incidence of death or adverse neurodevelopmental outcome for DC twins was 24.6\% compared to $20.0 \%$ for their matched singletons ( $p=$ 0.674; $p=0.439$, McNemar's test); for MC twins, it was $38.9 \%$ compared to $27.8 \%$ for their matched controls ( $p=$ $0.454 ; p=0.206$, McNemar's test).

\section{Discussion}

The incidence of twin pregnancies has increased substantially (Joseph, 1998; Ventura, 1997). Over the past decades,

\section{Table 9}

Distribution of Death and Neurodevelopmental Morbidity

\begin{tabular}{lccc}
\hline Value & $\begin{array}{c}\text { Monochorionic } \\
(n=36) \\
\#(\%)\end{array}$ & $\begin{array}{c}\text { Dichorionic } \\
(n=65) \\
\#(\%)\end{array}$ & $p$-value \\
& $14(38.9)$ & $16(24.6)$ & $0.173^{*}$ \\
death or impairment & $9(25.0)$ & $11(16.9)$ & 0.475 \\
Death & $(n=27)$ & $(n=54)$ & \\
\hline Vision impairment & $0(0)$ & $1(1.85)$ & 0.286 \\
Hearing impairment & $3(11.11)$ & $3(5.56)$ & 0.368 \\
Cerebral palsy & $3(11.11)$ & $2(3.70)$ & 0.363 \\
Cognitive impairment & $4(14.8)$ & $4(7.4)$ & 0.532 \\
\hline * Fisher's exact test & & &
\end{tabular}

many advances in obstetrical and neonatal care have taken place and it is now important to review current practices. Current literature focus on short-term outcomes such as perinatal and/or neonatality morbidity. Little is currently available to describe long term outcome of major neurodevelopmental parameters unless it is part of a larger scale study where twins are identified as a risk factor. Although there have been studies looking at aspects of outcome of twin pregnancies, few have taken the opportunity to look at the very small and immature twin and compare them to a singleton. Similarly, long term follow-up specifically looking at twins compared to singletons has been limited (Gardner, 1995).

Twin pregnancies have been reported to have increased morbidity, which can threaten the pregnancy and the fetuses. In this twin cohort, maternal morbidity was low compared to that of the singleton cohort. Although the differences in maternal morbidities were not significant, they were similar to what has been recently reported (Mizrahi, 1999). The different obstetrical modalities used to minimize morbidity were not evaluated in this study, therefore, it is difficult to ascertain the reasons for the lower incidence of maternal morbidity.

In this study, $35.6 \%$ of the pregnancies were monochorionic; although slightly higher, this is not out of keeping with what is currently being reported (Gaziano, 2000; Victoria, 2001). Our incidence of monochorionic pregnancies may reflect that the study center is a major perinatal referral center for the Central East region of Ontario and is likely to draw in more cases. The incidence of twin-to-twin transfusion syndrome for this cohort again is consistent with what is reported in the literature (Victoria, 2001). Mortality and morbidity are reported to be significantly higher in MC twins largely due to the effects of placental morphologic characteristics such vascular communications or sharing of a common placenta (Fox, 1997; Minakami, 1999; Wenstrom, 1992). In this study, MC pregnancies did not have a higher incidence in the more commonly reported maternal morbidities apart from growth restriction. Growth restriction occurred in $25.0 \%$ in $\mathrm{MC}$ pregnancies vs. $7.7 \%$ in the DC pregnancies, again in keeping with what has been reported in the literature (Gaziano, 2000). The degree of growth discrepancy has been related to a higher incidence of morbidity in the fetus (Cheung, 1995). The degree of growth discrepancy was not evaluated in this study because of the small sample size.

Birth weight has been shown to be one of the most important factors affecting perinatal mortality and is viewed as an important determinant of infant and longterm morbidity (Luke \& Keith, 1992; McCormick, 1985). Twins are often reported to be of lower birthweight as compared to singletons of comparable gestational age (Gardner, 1995) In this cohort, the twins group was slightly heavier. The incidence of infants with birth weights $<3$ rd percentile was equal between twins and singletons. The incidence of individual neonatal morbidity items assessed in this study did not differ significantly in the two groups. However, for all items except sepsis, the incidence was higher in twins suggesting an element of vulnerability with twins not seen in the singletons. MC twins were significantly smaller in 
birth weight and more immature than DC twins. Consequently, it was not surprising to see a higher incidence in neonatal morbidity. The relationship of a higher incidence of PDA because of monochorionicity is difficult to explain as it has never been reported and certainly warrants further investigation.

The use of dexamethasone in neonatal care to improve pulmonary outcomes in preterm infants has been under intense scrutiny in recent years (Barrington, 2001). This is largely due to a paucity of convincing evidence as to the clinical benefit and safety of dexamethasone. Recent trials are reporting an increase in rates of overall neurodevelopmental disability in neonates receiving dexamethasone (O’Shea, 1999; Shinwell, 2000; Stark, 2001; Yeh, 1998). In this study, the incidence of a poorer outcome was higher in those twins who received dexamethasone, which is in keeping with the results from clinical trials evaluating this medication. Because this study was not a randomized controlled trial, it is difficult to ascertain whether dexamethasone was a primary contributor to the poorer outcome or whether the infants were destined to have difficulties regardless of the use of dexamethasone.

Low birth weight is also a common risk factor for neurodevelopmental difficulties; this risk increases with declining birth weight (McCormick, 1985). Advances in obstetrical and neonatal care has led to an increase in survival in infants < 1500 grams and, in particular, infants < 1000 grams (Hack, 1996). This increase in survival may not be equated with an increase in intact outcome. Recent studies have shown that adverse neurodevelopmental outcomes for infants between 1000-1499 grams maybe 10-20\% (Piecuch, 1998). The incidence dramatically increases to $35-36 \%$ for infants under 28 weeks gestation (Battin, 1998). Multiple gestation was not necessarily found to be related to this increase in difficulties (Leonard, 1994).

Our results revealed a slightly higher mortality rate in the twins group (19.8\%) compared to the singletons $(11.8 \%)$ with the number of survivors with a severe neurodevelopmental deficit almost equal, 9.9\% vs. 10.8\%. In addition, this study revealed an incidence of mortality of $25.0 \%$ in the MC group vs. $16.9 \%$ in the DC group with an overall neurodevelopmental incidence of $13.8 \%$ in the MC group and $7.7 \%$ in the DC group. These figures are low compared to what has been reported, which is encouraging.

Cerebral palsy has been and remains a primary concern of neurodevelopmental difficulty in the preterm population. Studies have frequently associated a higher risk of cerebral palsy in twins and especially in monochorionic twins (Pharaoh, 1996; Pharaoh, 2001; Scheller, 1992; Williams, 1996). Our results suggested no significant difference between singletons $(4.5 \%)$ and twins (6.2\%). Similar results based on neurodevelopmental outcomes at 1 year corrected age have been reported (Gardner, 1995). The incidence of cerebral palsy among the survivors of the twins was $11.11 \%$ (MC twins) vs. $3.70 \%$ (DC twins). These figures are not out of keeping with $12 \%$ recently reported in a neonatal trial that evaluated indomethicin for the reduction of intraventricular hemorrhage (Schmidt, 2001).
It is important to note that even though these figures were not high, MC twins still presented with the higher incidence suggesting that the higher risk still persists with MC twins.

Cognitive difficulties are also presenting as an adverse outcome that has long-term impact. Recent studies have presented incidences as high as $25 \%$ in their study population (Schmidt, 2001). In this study, cognitive difficulties were the highest contributor to the overall combined neurodevelopmental difficulties at 18-24 months corrected age regardless of grouping. Although the developmental figures compare favorably with the literature, there is still a need for concern.

Twin-to-twin transfusion syndrome is repeatedly associated with adverse outcomes including death or severe neurodevelopmental outcomes (Cincotta, 2000). The incidence of $42.9 \%$ is consistent with reported literature.

This is not a randomized controlled trial, therefore it is open to selection bias. This study took into account only those twins and singletons admitted to the study site. The population, however, is representative of the infants cared for in both tertiary perinatal referral centers in metropolitan Toronto. The perinatal system in the Central East region is structured so that infants $\leq 30$ weeks are initially cared for in a tertiary center before returning to the referring community hospital for ongoing care until final discharge home.

The population in this cohort study is similar to those reported in other centers. Although statistically there was no difference between the groups analyzed in terms of the primary outcome, there was a trend with twins, in particular MC twins, as a group having a more adverse outcome, either death or severe neurodevelopmental morbidity, which may be clinically significant. Despite recent advances, twin-to-twin transfusion remains an ominous situation, especially for the small and immature twin.

Although there are some encouraging aspects of this study, there is still need for concern about the future of small, immature twins, especially from monochorionic pregnancies. The results, despite the study's limitations, can be used in counseling to parents. Adequate identification of chorionicity is still a vital component of twin pregnancy management. Parents need to be informed that there are risks for their very low birth weight premature twin, which require close developmental monitoring.

\section{Acknowledgments}

The authors would like to acknowledge the contribution of Terry Leeke, Database Consultant and Terri Myhr, Research Manager/Biostatistician at the Research Facilitation Office, Centre for Research in Women's Health, for data management, analysis and for reviewing drafts of the article.

\section{$\overline{\text { References }}$}

Barrington, K. J. (2001). Hazards of systemic steroids for ventilator-dependent preterm infants: What would a parent want? Canadian Medical Association Journal, 165(1), 33-34.

Battin, M., Ling, E. W., Whitfield, M. F., Mackinnon, M., \& Effer, S. B. (1998). Has the outcome for extremely low gestational age (ELGA) infants improved following recent advances 
in neonatal intensive care? American Journal of Perinatology, 8, 469-477.

Bayley, N. (1993). Bayley Scales of Infant Development (2nd ed). San Antonio: The Psychological Corporation, Harcourt Brace and Company.

Bell, M. J., Ternberg, J. L., Feigin, R. D., Keating, J. P., Marshall, R., Barton, L., \& Brotherton, T. (1978). Neonatal necrotizing enterocolitis: Therapeutic decisions based upon clinical staging. Annals of Surgery, 187, 1-7.

Burguet, A., Monnet, E., Pauchard, J. Y., Roth, P., Fromentin, C., et al. (1999). Some risk factors for cerebral palsy in very premature infants: Importance of premature rupture of membranes and monochorionic twin placentation. Biology of Neonate, 75(3), 177-86.

Cheung, V. Y., Bocking, A. D., \& Dasilva, O. P. (1995). Preterm discordant twins: What birth weight difference is significant?. American Journal of Obstetrics and Gynecology, 172(3), 955-959.

Cincotta, R. B., Gray, P. H., Phythian, G., Rogers, Y. M., \& Chan, F. Y. (2000). Long term outcome of twin-twin transfusion syndrome. Archives of Diseases in Children-Fetal Neonatal Edition, 83(3), F171-176.

Fanaroff, A. A., \& Martin, R. J. (1997). Neonatal-perinatal medicine: Diseases of the fetus and infant $\left(6^{\text {th }}\right.$ ed). St. Louis, Missouri: Mosby-Year Book.

Fox, H. (1997). Pathology of the placenta (2nd ed). Philadelphia: WB Saunders.

Gardner, M. O., Goldenberg, R. L., Cliver, S. P., Tucker, J. M., Nelson, K. G., \& Copper, R. L. (1995). The origin and outcome of preterm twin pregnancies. Obstetrics \& Gynecology, 85(4), 553-557.

Gaziano, E. P., De Lia, J. E., \& Kuhlmann, R. S. (2000). Diamnionic monochorionic twin gestations: An overview. Journal of Maternal Fetal Medicine, 9(2), 89-96.

Hack, M., Friedman, H., \& Fanaroff, A. A. (1996). Outcomes of extremely low birth weight infants. Pediatrics, 98(5), 931-937.

Joseph, K. S., Kramer, M. S., Marcoux, S., et al. (1998). Determinants of preterm birth rates in Canada from 1981 through 1983 and from 1992 through 1994. New England Journal of Medicine, 339, 1434-1439.

Leonard, C. H., Piecuch, R. E., Ballard, R. A., \& Cooper, B. A. (1994). Outcomes of low birth weight infants: Multiple gestation versus singletons. Pediatrics, 93(4), 611-615.

Luke, B., \& Keith, L. G. (1992). The contribution of singletons, twins and triplets to low birth weight, infant mortality and handicap in the United States. Journal of Reproductive Medicine, 37, 661-666.

MacDorman, M. F., \& Atkinson, J. (1999). Infant mortality statistics from the 1997 period linked birth/infant death data set. National Vital Statistics Report, 47, 1-23.

McCormick, M. C. (1995). The contribution of low birth weight to infant mortality and childhood morbidity. New England Journal of Medicine, 312, 82-90.

Minakami, H., Honma, Y., Matsubara, S., Uchida, A., Shiraishi, H., \& Sato, I. (1999). Effects of placental chorionicity on outcome in twin pregnancies. Journal of Reproductive Medicine, 44, 595-600.
Mizrahi, M., Furman, B., Shoham-Vardi, I., Vardi, I., Maymon, E., \& Mazor, M. (1999). Perinatal outcome and peripartum complications in preterm singleton and twin deliveries: A comparative study. European Journal of Obstetric and Gynecological Reproductive Biology, 87(1), 55-61.

O’Shea, T. M., Kothadia, J. M., Klinepeter, K. L., Goldstein, D. J., et al. (1999). Randomized placebo-controlled trial of a 42 day tapering course of dexamethasone to reduce the duration of ventilator-dependency in very low birth weight infants: Outcome of study participants at 1 -year adjusted age. Pediatrics, 104, 15-21.

Pharaoh, P. O., \& Cooke, T. (1996). Cerebral palsy and multiple births. Archives of Diseases in Children- Fetal Neonatal Edition, 75(3), F174-177.

Pharaoh, P. O. (2001). Twins and cerebral palsy. Acta Paediatrica Supplement, 90(436), 6-10.

Piecuch, R. E., Leonard, C. H., \& Cooper, B. A. (1998). Infants with birth weight 1000-1499 grams born in three time periods: Has outcome changed over time? Clinical Pediatrics (Philadelphia), 37(9), 537-545.

Powers, W. F., \& Kiely, J. L. (1994). The risks confronting twins: A national perspective. American Journal of Obstetrics and Gynecology, 170(2), 456-461.

Robertson, P. A., Sniderman, S. H., Laros, R. K., Jr., Cowan, R., Heilbron, D., Goldenberg, R. L., Iams, J. D., \& Creasy, R. K. (1992). Neonatal morbidity according to gestational age and birth weight from five tertiary care centers in the United States, 1983 through 1986. American Journal of Obstetrics and Gynecology, 166(6 pt 1), 1629-1641.

Scheller, J. M., \& Nelson, K. B. (1992). Twinning and neurologic morbidity. American Journal of Diseases in Childhood, 146(9), 1110-1113.

Schmidt, B. K., Davis, P., Moddeman D., Ohlsson, A., Roberts, R. S., Saigal, S., Solimono, A., Vincer, M., \& Wright, L. L. (2001). Long-term effects of indomethicin prophylaxis in extremely-low-birth-weight infants. New England Journal of Medicine, 344(26), 1966-1972.

Shinwell, E. S., Karplus, M., Reich, D., et al. (2000). Early postnatal dexamethasone treatment and increased incidence of cerebral palsy. Archives of Diseases in Children - Fetal Neonatal Edition, 83(3), F177-181.

Sonntag, J., Waltz, S., Schollmeyer, T., Schuppler, U., Schroder, H., \& Weisner, D. (1996). Morbidity and mortality of discordant twins up to 34 weeks of gestational age. European Journal of Pediatrics, 155(3), 224-9.

Stark, A. R., Carlo, W. A., Tyson, J. E., Papile, L. A., et al. (2001). Adverse effects of early dexamethasone treatment in extremely-low-birth-weight infants. New England Journal of Medicine, 344(2), 95-101.

The Committee for the Classification of Retinopathy of Prematurity. (1984). An international classification for retinopathy of prematurity. Archives of Ophthalmology, 102, 1130-1134.

Usher, R., \& McLean, F. (1969). Intrauterine growth of live-born caucasian infants at sea level: Standards obtained from measurements on 7 dimensions of infants born between 25 and 44 weeks of gestation. Journal of Pediatrics, 74, 901-910.

Ventura, S. J., Martin, J. A., Curtain, S. C., \& Mathews, T. J. (1999). Births: Final data for 1997. National Vital Statistics Report, 47(18), 1-96. 
Volpe, J. J. (1995). Intracranial hemorrhage: Germinal matrixintraventricular hemorrhage of the premature infant. In J. J. Volpe (Ed.), Neurology of the Newborn (3rd ed.; pp. 422-425). Philadelphia: WB Saunders Company.

Victoria, A., Mora, G., \& Arias, F. (2001). Perinatal outcome, placental pathology, and severity of discordance in monochorionic and dichorionic twins. Obstetrics and Gynecology, 97(2), 310-315.

Wenstrom, K. D., Tessen, J. A., Zlatnik, F. J., \& Sipes, S. L. (1992). Frequency, distribution, and theoretical mechanisms of hematologic and weight discordance in monochorionic twins. Obstetrics and Gynecology, 80, 257-261.

Williams, K., Hennessy, E., \& Alberman, E. (1996). Cerebral palsy: Effects of twinning, birthweight, and gestational age. Archives of Diseases in Children - Fetal Neonatal Edition, 75(3), F178-182.

Yeh, T. F., Lin, Y. J., Huang, C. C., Chen, Y. J., et al. (1998). Early dexamethasone therapy in preterm infants: A follow-up study (article online). Pediatrics, 101(5), e7. 